\title{
The Knowledge, Attitude, and Practice (KAP) of Women Health Services Staff About Risk Factors of Cardiovascular Diseases (CVDs) in City of Fereydan and Chadegan, Iran
}

\author{
Arash Salahshoori ${ }^{1,}$; Mostafa Nasirzadeh ${ }^{2}$; Javad Haruni ${ }^{3}$; Fatemeh Pourhaji ${ }^{4}$; Sara \\ Salahshoori ${ }^{5}$; Jasem Nozarpoor ${ }^{6}$ \\ ${ }_{2}^{1}$ Health Education Unit, Health and Treatment Center of Izeh, Departments of Health Education and Promotion, Isfahan University of Medical Sciences, Isfahan, IR Iran \\ ${ }_{3}^{2}$ School of Health, Shahid Beheshti University of Medical Sciences, Tehran, IR Iran \\ ${ }^{3}$ Health Education Unit, Health and Treatment Center of Dena, Departments of Health Education and Promotion, Shahid Beheshti University of Medical Sciences, Tehran, IR Iran \\ ${ }_{5}^{4}$ School of Health, Mashhad University of Medical Sciences, Mashhad, IR Iran \\ ${ }^{5}$ School of Educational Sciences, Shahid Chamran University of Ahvaz, Ahvaz, IR Iran \\ 6 School of Nursing, Jundishapur University of Medical Sciences Ahvaz, Ahvaz, IR Iran \\ ${ }^{*}$ Corresponding author: Arash Salahshoori, Health Education Unit, Health and Treatment Center of Izeh, Departments of Health Education and Promotion, Isfahan University of \\ Medical Sciences, Isfahan, IR Iran, E-mail: aidin_salahshoori@yahoo.com
}

Received: June 28, 2014; Revised: September 2, 2014; Accepted: November 14, 2014

Background: Inadequate knowledge and lack of its transmission to the community from health services staff is one of the factors of failure in preventing cardiovascular disease.

Objectives: Thus we aimed to determine the knowledge, attitude and practice of health services staff in relation to prevention of cardiovascular diseases.

Patients and Methods: In this descriptive and analytic study, performed during the year 2012, subjects included 185 women health services staff (Including Physicians, Nurses, Midwives, Health experts and Health workers) from Fereydan and Chadegan city. The data collection tool was questionnaires including demographic characteristics and questions about knowledge, attitude and practice. For statistical analysis the SPSS20 software, descriptive statistics and statistical tests were used.

Results: Mean percentage of knowledge, attitude and practice scores of health services staff were $56.48 \pm 9.89,67.01 \pm 5.46$ and $37.56 \pm$ 20.30 , respectively. Regarding the risk factors for cardiovascular disease $2.7 \%$ of the participants had good and $36.2 \%$ had poor knowledge. Furthermore, $4.9 \%$ had good attitude, $0.5 \%$ had poor attitude, $82.2 \%$ had poor practice, and only $1.1 \%$ had good practice.

Conclusions: Knowledge, attitude and practice of subjects were not desirable. Therefore, we recommend preparation and appropriate educational booklets for health services staff and quality retraining courses in this field along with evaluation at the end of the retraining courses and also activate physicians training of other health care personnel.

Keywords:Knowledge; Attitude; Cardiovascular Disease

\section{Background}

Cardiovascular diseases are one of the most important problems of modern societies and the most common cause of death in most countries (1). These diseases are the main cause of death in the Unites states and each year about $30 \%$ of deaths in this country occur due to these diseases (2). According to the available evidence, in our country also, cardiovascular diseases are considered as a substantial social and health problem and their impacts are increasing rapidly (3). According to the World Health Organization (WHO) reports, in our country, 41.3\% of all deaths in 2005 have been due to cardiovascular diseases and it is anticipated that until 2030, this number will reach $44.8 \%$ (4). In addition, because of urbanization and machine dependent lifestyles, in the near future the prevalence of these diseases will increase (5). People with these diseases may face major changes in their relation- ships, work, values, social, physical abilities and self-care abilities and therefore their general health will be undermined (6). In the recent decades, the number of patients with cardiovascular diseases has increased dramatically and these diseases have been the first cause of disability and death in developed countries. Thus, in most countries, cardiovascular disease prevention and control is considered as one of the national and governmental duties (7). There are a lot of risk factors related to cardiovascular diseases, some being modifiable. Modifiable risk factors include lifestyle-related factors such as physical activity, diet, smoking and alcohol consumption. By eliminating any of the mentioned factors, the probability of cardiovascular diseases will decreased (8). In the recent years, determining the risk factors and finding ways to modify them, by interventional methods, have been the main topic of re-

Copyright (C) 2015, Ahvaz Jundishapur University of Medical Sciences. This is an open-access article distributed under the terms of the Creative Commons Attribution-NonCommercial 4.0 International License (http://creativecommons.org/licenses/by-nc/4.0/) which permits copy and redistribute the material just in noncommercial usages, provided the original work is properly cited. 
searches (9). According to the results of these studies, if people's awareness of symptoms and risk factors of coronary heart disease is raised, in case of incidence of symptoms and risk factors, the subject will be more capable of dealing with the illness (10). In health education, it is very important to notify people about causes of the disease and methods of prevention. Education programs should be planned according to people's knowledge, awareness, customs, beliefs and behaviors. Education should begin once the characteristics of the society are specified (11). Despite the importance of cardiovascular diseases and the necessity of health-care workers' awareness of its risk factors, unfortunately no comprehensive investigation on their awareness, attitude and practice regarding cardiovascular diseases have been conducted in our country. Results of a study conducted in 1994 showed that general practitioners awareness of cardiovascular diseases in Isfahan is not enough (12). In addition, various studies have shown that one of the reasons of failure to prevent cardiovascular diseases is inadequate knowledge of physicians and other health-care workers and failure in transferring information about risk factors to the society (13). Considering the importance of health-care workers' awareness of cardiovascular diseases risk factors, it seems necessary to conduct research in order to assess their awareness, attitude and practice for prevention of cardiovascular diseases.

\section{Objectives}

Therefore the present study was conducted on female health-care workers, working in Fariden and Chadegan health centers of the Isfahan province.

\section{Patients and Methods}

This was a descriptive-analytic study on female healthcare workers of Fariden and Chadegan health centers, located in the Isfahan province. After conducting the required coordination, 185 volunteer female health-care workers participated in this study. The data collection tool was a questionnaire that was designed according to objectives and hypothesis of the research, previous studies in this field, international studies and experts' opinion. This questionnaire included four sections:

Section 1: personal information questions including ten questions about age, education level, marital status, job, height, weight, place of residence, nativity status, job experience and number of children.

Section 2: awareness-related questions including 14 questions that assessed the staff's awareness of cardiovascular diseases.

Section 3: attitude-related questions, which included 28 questions.

To score awareness questions, the correct answers had 1 point and incorrect answers and "I don't know" had 0 point. For attitude questions which included five multichoice answers in the Likertscale(from completely agree to completely disagree), for "completely disagree” one point, "disagree" two points, "No idea" three points, "agree" four points and "completely agree" five points were given. For "reverse" phrases, the scoring was vice versa.

Section 4: in practice questions, which were in form of self-reporting and had binary answers (Yes and No), the decided point for "Yes" was 1 and for "No" was 0 . Eventually scores of all three sections (awareness, attitude and practice) were calculated as percentages. Therefore the minimum and maximum were 0 and 100 percent, respectively.

The categorization of awareness scores was as follows:

Scores between 11-14 (75-100\%) = good

Scores between 7-10 (50-75\%) = moderate

Scores less than 7 (less than $50 \%$ ) = poor

The categorization of attitude scores was as follows: Scores between 105-140 (75-100 \% ) = positive attitude Scores between 70-105 (50-75\%) = moderate

Scores less than 70 (less than 50\%)= poor attitude

Categorization of practice scores was as follows:

Scores between $75-100 \%=$ good

Scores between $50-75 \%=$ moderate

Scores less than $50 \%=$ weak practice

To assess the validity of the questionnaire, we gave five questionnaires to fiveacademic members in health education and nutrition fields and they approved its validity. To assess the reliability of the questionnaire, we performed a pilot study on 20 staff members of health centers. In addition, by using internal consistency, the Cronbach's alpha for each section was calculated as follows:

Awareness questions: $\alpha=0.81$

Attitude questions: $\alpha=0.85$

Practice questions: $\alpha=0.81$

After completion of the questionnaires by the staff and transfer of the data into the SPSS software, the data was analyzed using descriptive statistics and Chi-square, oneway analysis of variance and Pearson's correlation tests. The significance level for this study was set at 0.05 .

\section{Results}

Overall, 185 health-care workers participated in this study. Amongst these participants, 134 (72.4\%) were married and 48 (25.9\%) were single. There were six (3.2\%) physicians, 14 (7.6\%) nurses, 40 (21.6\%) midwives, 70 (37.8\%) rural primary health-care workers (known as Behvarz in Iran), as well as, 27 (14.6\%) participants with bachelor's degree in health and 28 (15.1\%) with associate's degree in health. The participants' age was between 25 and 50 years with the mean of $32.1 \pm 5.62$ years. Furthermore, 131 participants (70.8\%) lived in the city and the rest lived in villages. The participants' body mass index (BMI) was between 15.79 and 39.64 with a mean of $25.22 \pm 4.27$. Body mass index of $14.6 \%$ of the participants was more than 30 (Table 1).

The participants' minimum and maximum awareness scoresfor cardiovascular diseases risk factors were three and eleven, respectively with the mean score of $56.48 \pm$ 9.98. Five (2.7\%) participants had good awareness, 113 (61.1\%) 
Salahshoori A et al.

had moderate and 67 (36.2\%) had poor awareness. The highest awareness score belonged to physicians which was $60.71 \pm 11.73$. The assessment of health-care workers' awareness of cardiovascular risk factors in Fariden and Chadegan health centers showed that $96.2 \%$ considered diabetes as one of the risk factors of heart disease. Furthermore, $84.3 \%$ of the studied participants were aware of preventive effects of fruit and vegetable consumption on cardiovascular diseases and 935 people were aware of the harmful effects of smoking cigarette and shisha. Another issue that was investigated by this research was the staff's awareness of the role of physical activities in cardiovascular diseases prevention, where $100 \%$ of the staff were aware of this this role. Only $40 \%$ of the participants were aware of the health benefits of liquid oil and $45.4 \%$ of the subjects knew the normal blood cholesterol level. According to the findings, participants' minimum and maximum attitude score was 68 and 130 with a mean of $67.01 \pm 5.46$. Nine (4.9\%) participants had good attitude, 175 (94.6\%) had moderate and one person (0.5\%) had poor attitude. The highest attitude score belonged to nurses which was 68.46 \pm 4.09 . In addition, regarding the subjects' practice, the mean score was $37.56 \pm 20.30$. Overall, 152 people $(82.2 \%)$ had good practice, 31 people (16.8\%) had moderate and only two people (1.1\%) had bad practice. In this study, the highest practice score belonged to midwives ( $40 \pm 20.25)$. Table 2 compares health-care workers' awareness, attitude and practice scores in various occupations. Table 3 also shows the frequency and percentage of health-care workers who had correct practice for preventing heart diseases. Regarding correct practice, liquid oil consumption (71.9\%) had the greatest percentage while blood sugar control (5.4\%) had the lowest percentage.
Table 1. The Frequency Distribution of Demographic Characteristics of Studied Female Health-Care Workers of Fariden and Chadegan

\begin{tabular}{|lc}
\hline Variable & No. $(\%)$ \\
\hline Marital status & $134(72.4)$ \\
\hline Married & $48(25.9)$ \\
\hline Single & $2(1.1)$ \\
\hline Divorced & $1(0.5)$ \\
\hline Widowed & \\
\hline Age, yr & $79(42.7)$ \\
\hline $20-30$ & $96(51.9)$ \\
\hline $31-40$ & $10(5.4)$ \\
\hline $41-50$ & \\
\hline BMI, kg/m 2 & $8(4.3)$ \\
\hline$<18.5$ & $89(48.1)$ \\
\hline $18.5-24.9$ & $61(33)$ \\
\hline $25-29.9$ & $27(14.6)$ \\
\hline$\geq 30$ & \\
\hline Place of residence & $131(70.8)$ \\
\hline City & $54(29.2)$ \\
\hline Village & \\
\hline Nativity & $127(68.6)$ \\
\hline Native & $58(31.4)$ \\
\hline Non-native & \\
\hline Job & $6(3.2)$ \\
\hline Physician & $14(7.6)$ \\
\hline Nurse & $40(21.6)$ \\
\hline Midwife & $27(14.6)$ \\
\hline Staff with bachelor's degree in health & $28(15.1)$ \\
\hline Staff with associate's degree in health & $70(37.8)$ \\
\hline Behvarz & \\
\hline & \\
\hline
\end{tabular}

\begin{tabular}{|c|c|c|c|c|c|c|c|c|c|}
\hline Group & Physician & \multicolumn{2}{|c|}{ Nurse } & Midwife & $\begin{array}{l}\text { Staff With Bachelor's } \\
\text { Degree in Health }\end{array}$ & $\begin{array}{l}\text { Staff With Associate's } \\
\text { Degree in Health }\end{array}$ & Behvarz & Total & P Value \\
\hline Awareness & $73.11 \pm 71.60$ & \multicolumn{2}{|c|}{$54.08 \pm 10.375$} & $55.35 \pm 11.74$ & $57.14 \pm 9.07$ & $55.35 \pm 9.44$ & $57.44 \pm 9.05$ & $56.48 \pm 9.89$ & 0.6 \\
\hline Attitude & $11.3 \pm 30.66$ & \multicolumn{2}{|c|}{$68.46 \pm 4.09$} & $66.78 \pm 5.76$ & $67.16 \pm 5.19$ & $66.14 \pm 8.02$ & $67.19 \pm 4.57$ & $67.01 \pm 5.46$ & 0.8 \\
\hline Practice & $25.09 \pm 38.88$ & \multicolumn{2}{|c|}{$39.28 \pm 15.47$} & $40 \pm 20.25$ & $30.86 \pm 21.53$ & $34.52 \pm 19.73$ & $39.52 \pm 20.49$ & $37.56 \pm 20.3$ & 0.4 \\
\hline \multicolumn{10}{|c|}{$\begin{array}{l}\text { Table 3. Comparison of the Frequency of Correct Practice Answers Regarding Cardiovascular Diseases Risk Factors According to } \\
\text { Health-Care Workers' Occupation a }\end{array}$} \\
\hline \multirow{2}{*}{\multicolumn{2}{|c|}{ Practice }} & \multicolumn{8}{|c|}{ Occupation group } \\
\hline & & hysician & Nurs & e Midwife & $\begin{array}{l}\text { Staff with bachelor's } \\
\text { degree in health }\end{array}$ & $\begin{array}{l}\text { Staff with associate's } \\
\text { degree in health }\end{array}$ & Behvarz & Total & P Value \\
\hline \multicolumn{2}{|c|}{ Blood sugar control } & 0 & 0 & 2.5 & 3.7 & 0 & 11.4 & 5.4 & 0.07 \\
\hline \multicolumn{2}{|c|}{$\begin{array}{l}\text { Fruit and vegetable } \\
\text { consumption }\end{array}$} & 50 & 50 & 60 & 48 & 46 & 50 & 51.4 & 0.8 \\
\hline \multicolumn{2}{|c|}{$\begin{array}{l}\text { Smoking (cigarette } \\
\text { or shisha) }\end{array}$} & 0 & 0 & 5 & 0 & 0 & 4.3 & 2.7 & 0.3 \\
\hline \multicolumn{2}{|c|}{ Physical activity } & 50 & 14.3 & 50 & 25.9 & 42.9 & 38.6 & 38.4 & 0.1 \\
\hline \multicolumn{2}{|c|}{$\begin{array}{l}\text { Liquid oil consump- } \\
\text { tion }\end{array}$} & 83.3 & 85.7 & 65 & 59.3 & 67.9 & 78.6 & 71.9 & 0.2 \\
\hline \multicolumn{2}{|c|}{$\begin{array}{l}\text { Blood cholesterol } \\
\text { control }\end{array}$} & 50 & 85.7 & 57.5 & 48.1 & 50 & 54.3 & 55.7 & 0.2 \\
\hline
\end{tabular}

\footnotetext{
$\mathrm{a}$ Data are presented as $\%$.
} 


\section{Discussion}

Since in our literature review we did not find any related research on health-care workers, we will compare our results with the results of studies on other groups. According to the results of this study, although health-care workers' awareness score was $56.48 \pm 9.89$, which is moderate, $36.2 \%$ had a poor awareness score. In a research conducted in Isfahan during the year 1994, it was revealed that general practitioners' awareness of cardiovascular diseases risk factors is inadequate (12). Results of a study in Saudi Arabia also showed that the majority of social health staff and nurses had a poor knowledge of hypertension (14). As indicated by Table 2, physicians' awareness of cardiovascular diseases risk factors is higher than other groups and this finding is consistent with the results of Sajjadi et al.'s study in 2008 (15). Since people mostly acquire their information about cardiovascular diseases from healthcare workers, the poor awareness of health-care workers in this field would have negative impacts on educational interventions that are performed to prevent these diseases. Moreover, it was shown that only $4.9 \%$ of the studied participants had a positive attitude towards controlling cardiovascular diseases risk factors. In a study conducted by Alimohammadi et al. in Ardabil (16) this number was $51.3 \%$ and in Jalali et al.'s study, it was reported as 6.5\% (10). According to the results of our study, $94.6 \%$ of the studied individuals had a moderate score for attitude towards controlling cardiovascular diseases risk factors. Results of a study conducted in South Africa showed that most of the studied health-care workers had a poor attitude towards hypertension and drug therapy (17), yet the findings of Steptoe's study showed that most of the general practitioners and nurses had a good attitude towards cardiovascular diseases prevention, especially hypertension prevention (18). Results of this study showed that $1.1 \%$ of the subjects had good practice in preventing cardiovascular diseases risk factors and $82.2 \%$ had poor practice in this regard. The results of a study from Saudi Arabia indicated that despite of having good attitude, most of nurses had poor practice in regards to hypertension screening (19). Findings of this study showed that $96.2 \%$ of the staff believed that diabetes is a risk factor of heart disease. On the other hand, only $5.4 \%$ of the participants had checked their blood sugar during the previous year. According to the results of this research, $84.3 \%$ of the staff was aware of the effects of fruit and vegetable consumption on cardiovascular diseases prevention yet only $51.4 \%$ reported that during the last week, they had consumed five or more servings of fruits and vegetables. The results of numerous researches suggest that practice is affected by awareness and some other important factors including economic limitations and cultural customs. Although there is obvious evidence for the preventive effects of fruits and vegetables consumption, in both developed and developing countries they are consumed inadequately (20). Sometimes lack of access to healthy foods influences nutritional behaviors (21). In this study $59.5 \%$ of the participants mentioned that the high price of healthy foods is one of the barriers of having a healthy diet. Staff's awareness regarding the role of smoking in the incidence of cardiovascular diseases was good; 93.3\% of the participants were aware of the harmful effects of smoking cigarette and shisha on coronary artery disease and only $2.7 \%$ of the subjects reported that during the last week they had smoked cigarette, shisha or tobacco. Results of an investigation on people's awareness of the dangers of smoking in Ardabil showed that $41.4 \%$ of the subjects believed that smoking is a risk factor for heart disease, yet their practice showed that $24 \%$ were cigarette smokers (16). According to the results of this study, 100\% of the participants were aware of the effects of inactivity on coronary heart disease, which means they had good knowledge in this regard yet their practice in doing physical activity was not good, such that only $38.4 \%$ of the staff had regular physical activity. One of the reasons for this inappropriate practice is the existence of some barriers for performing physical activity. In the present study, $54.1 \%$ of the participants claimed that not having a suitable place and $38.4 \%$ claimed not having enough time as reasons of inactivity. An investigation on a statistical population in Tehran also showed that $30.1 \%$ of the subjects exercised yet $69.9 \%$ had no physical activity (16). It may be that the staff's higher awareness is due to their occupational need to have more information about heart disease yet changing lifestyle and habits is very difficult and therefore their practice is not as good as their level of awareness. In this study, the subject's awareness about liquid oil consumption as a preventive factor of cardiovascular disease was investigated; the staff's awareness was not good and although $71.9 \%$ were consuming this product, only $40 \%$ were aware of its health benefits. In addition, $45.4 \%$ of the subjects said that the normal level of blood cholesterol is a heart disease risk factor and 55.7\% had checked their blood cholesterol level during the previous year. In this study, a positive relationship between "awareness and attitude" and also between "awareness and practice" was observed yet these relationships were not statistically significant. No statistically significant association between attitude towards cardiovascular disease risk factors and subjects' practice was observed. Based on the obtained results from this study, the awareness, attitude and practice of the studied subjects about cardiovascular diseases risk factors was not good. Since people get their information about cardiovascular diseases from health-care workers and regarding the importance of these diseases as the main cause of death in our country and in most of developing and developed countries, it seems necessary to set interventional measures to raise health-care workers' awareness and correct their practice in preventing these diseases. Therefore it is recommended to conduct educational programs and 
perform high quality retraining courses for health-care workers. It is also recommended to activate physicians to educate other health-care staffs and evaluate them at the end of retraining courses. Although we assured all staff about the confidentiality of their personal information, most refused to participate in this study, because they were afraid of their inadequate awareness, attitude and practice about cardiovascular disease risk factors and this was one of the limitations of this research.

\section{Acknowledgements}

The authors of this article appreciate the assistance ofthe managers of Fariden and Chadegan health centers, physicians, nurses, midwives, health staffs, health workers and all those involved in this research.

\section{Funding/Support}

The cost of this research was provided by the first Author of the article.

\section{References}

1. Malkzadh M., Ghaffarian Shirazi H, Momeni-Nejad M, Zadehbaghri G, Sharifi B, Jabbarnejad A. General Health variations, in patients with MI, longitudinal case-control nested design. Zahedan J Res Med Sci. 2012;13(9):1-7.

2. Winham DM, Jones KM. Knowledge of young African American adults about heart disease: a cross-sectional survey. BMC Public Health. 2011;11(1):248.

3. Azizi F, Hatami H, Janghorbani M. Epidemiology and control of Common disease in Iran.Tehran: Eshtiagh Publishing; 2001.

4. Imanipoor M, Haghani H. [Evaluation of culturals knowledge and practice in the prevention of cardiovascular disease and some related factors]. J Nur Midwifery. 2008;18(60):36-44.

5. Tavakoli HR, Sanaei Nasab H, Karimi AA, Tavakoli R. Study of knowledge, attitude, and practice towards proper model of foods and nutrition by Military formal personnel. Mil Med J. 2008;10(2):129-36.

6. O'Donnell L. Complications of MI beyond the acute stage. Am J Nurs. 1996;96(9):25-30.
7. Sabzevari S, Mohammadalizade S, Borhani P, Pishcar Mofrad Z. Kerman population,s Knowledge,attitude and practice about prevention of Myocardial Infarction.J Rafsanjan Univ Health Med Sci. 2002;1(4):275-84.

8. Mackay J, Mensah GA. The atlas of heart disease and stroke. Geneve: World Health Organization; 2004.

9. al-Adsani A, Memon A, Peneva A, Baidas G. Clinical epidemiology of acute myocardial infarction in Kuwait. Acta Cardiol. 2000;55(1):17-23.

10. Jalali F, Hajiahmadi M, Hossianpour M, Angri MZ, Asadi A. [Knowledge, attitude and practice of people living in Babol about clinical symptoms and risk factors of coronary artery diseases]. J Babol Univ Med Sci. 2003;6(1):43-9.

11. Sadeghi Hasan Abadi A. [General public health]. Dept Reds Med Sci Health Care Serv Univ Fars Province. 1994:215-22.

12. Farhad M, Moazzam E, Faghih-Imany E, Sarrafzadegan N. A study of knowledge-attitude and practice of general practitioners regarding risk factors of cardiovascular disease. J Isfahan Univ Med Sci. 1999;3(4):286-9.

13. Hu SP, Wu MY, Liu JF. Nutritional knowledge and attitudes of physicians. J Am Diet Assoc. 1994;70(6):607-9.

14. Ahmed ME. Knowledge of blood pressure measurement among a teaching hospital staff in a developing nation.J Hum Hypertens. 1997;11(8):495-9.

15. Sajjadi F, MohammadiFard N, Khosravi A, Bahonar A, Maghroon M, Fathi M, et al. Nutritional knowledge attitude and practice of health professionals about cardiovascular diseases.J Birjand Univ Med Sci. 2008;15(2):65-72.

16. Alimohammadi M, Doustkami H, Dadkhah B, Sezavar S. Survey of knowledge, attitude and practice of Ardabil citizens about risk factors of coronary artery disease . J Ardabil Univ Med Sci. 2001;1(4):42-8.

17. Sengwana MJ, Puoane T. Knowledge, beliefs and attitudes of community health workers about hypertension in the Cape Peninsula, South Africa. Curationis. 2004;27(1):65-71.

18. Steptoe A, Doherty S, Kendrick T, Rink E, Hilton S. Attitudes to cardiovascular health promotion among GPs and practice nurses. Fam Pract. 1999;16(2):158-63.

19. Al-Khashman AS. Screening for hypertension. Assessing the knowledge, attitudes and practice of primary health care physicians in Riyadh, Saudi Arabia. Saudi Med J. 2001;22(12):1096-100.

20. Variyam JN, Blaylock J, Smallwood DM. Modelling nutrition knowledge, attitudes, and diet-disease awareness: the case of dietary fibre. Stat Med.1996;15(1):23-35.

21. Derrickson JP, Sakai M, Anderson J. Interpretations of the "balanced meal" household food security indicator. J Nutr Educ. 2001;33(3):155-60. 